NASA Technical Memorandum 101315

\title{
Assessment of the Effects of Space Debris and Meteoroids Environment on the Space Station Solar Array Assembly
}

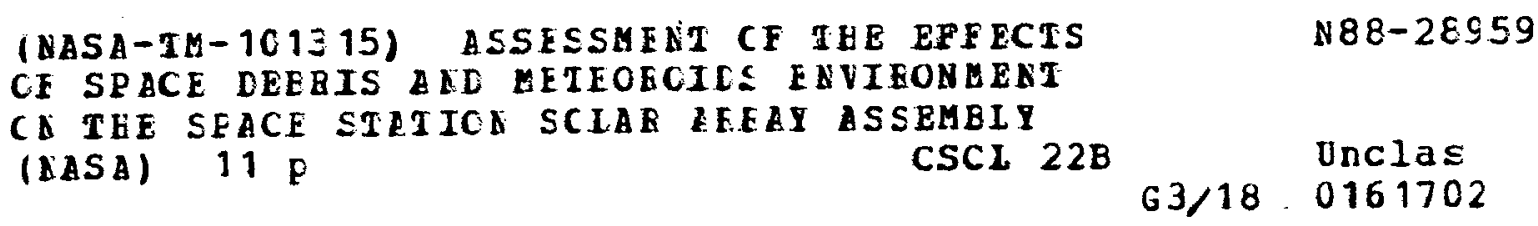

Henry K. Nahra

Lewis Research Center

Cleveland, Ohio

Prepared for the

20th Photovoltaic Specialists Conference

sponsored by the Institute of Electrical and Electronics Engineers

Las Vegas, Nevada, September 26-30, 1988 
Trade names or manufacturers' names are used in this report for identification only. This usage does not constitute an official endorsement, either expressed or implied, by the National Aeronautics and Space Administration. 


\section{ASSESSMENT OF THE EFFECTS OF SPACE DEBRIS AND METEOROIDS ENVIRONMENT ON THE SPACE STATION SOLAR ARRAY ASSEMBLY}

Henry K. Nahra

National Aeronautics and Space Administration Lewis Research Center

Cleveland, Ohio 44135

ABSTRACT

In this paper, the methodology used to assess the probability of no impact of space debris and meteoroids on a spacecraft structure was applied to the space station solar array assembly. Starting with the space debris and meteoroids flux models, the projected surface area of the solar cell string circuit of the solar array panel and the mast longeron, and the design lifetime, the probability of no impact on the solar array mast and solar cel.l string circuits was determined as a function of particle size. The probability of no impact on the cell string circuits was used to derive the probability of no open circuit panel. The probability of meeting a certain power requirement at the end of the design lifetime was then calculated as a function of impacting particle size. Coupled with a penetration and damage models/correlations which relate the particle size to the penetration depth and damage, the results of this analysis can be used to determine the probability of meeting the power requirement given a degree of redundancy, and the probability of no impact on the solar array mast.

\section{INTRODUCTION}

The meteoroids and debris environments consist of particles of different diameter and density moving at high velocities in the space environment. Micrometeoroids range in size from $10^{-4}$ to $10 \mathrm{~cm}$, with a mean density of $0.5 \mathrm{~g} / \mathrm{cm}^{3}$, and a mean velocity of about $20 \mathrm{~km} / \mathrm{sec}$. Although micrometeoroids originate from cometary and lunar sources, space debris are man made and range in size from microscopic particles to particles of $100 \mathrm{~cm}$ in effective diameter. Since space debris originate from useless orbiting spacecrafts, they exhibit an average orbital velocity of $g$ to $10 \mathrm{~km} / \mathrm{sec}$ depending on the orbital inclination, with an average mass density of $2.8 \mathrm{~g} / \mathrm{cm}^{3}$ for particles less than $1 \mathrm{~cm}$ in diameter. Micrometeoroids and space debris flux models (Fig. 1) can be used to estimate the flux of certain particle diameter or greater (1). The concern for the damage resulting from the impact of particles moving with hypersonic velocities necessitates the assessment of the number of impacts and their effects on the space station photovoltaic solar array integrity and performance.
The purpose of this paper is to analytically assess the probability of success of the space station solar array components (or subassemblies such as the solar array mast and blanket) as a function of the impacting particle diameter for both meteoroids and debris environments. Probability of success of the mast is defined as the probability that the mast meets the lifetime requirement with no impact-induced failure. Probability of success of the blanket is defined as the probability that the blanket meets the power requirement over the mission duration. Determination of the penetrating particle size and correlation of the particle size and damage are not presented in this paper due to the lack of such data as applied to the solar array structure and materials.

\section{DESCRIPTION OF THE SPACE STATION SOLAR ARRAY}

The space station solar array consists of two photovoltaic blankets for power generation, a mast for blanket deployment, a canister for mast stowage, two blanket boxes for blanket stowage during launch, and a deployment mechanism for on-orbit array deployment. Each blanket consists of active panels structurally connected by hinge pins. Each panel contains solar cells interconnected by printetched copper circuits encapsulated between two Kapton 1 layers. The cells are welded to the copper pads and mounted on the Kapton substrate by an adhesive (2). The space station solar array is lllustrated in Fig. 2 (3). Figure 3 shows the repeating units that were used to analyze the probability of success (or probability of meeting a power or lifetime requirement) of the mast and blanket of the solar array. These units are the mast bay and the cell string of the panel.

\section{ANALYSIS}

\section{Solar Array Mast}

The mast and blanket subassemblies of the solar array were under consideration in this analysis. To quantify the impact assessment on the

1Registered trademark of E.I. Dupont De Nemours and Co., Inc. 
solar array mast, the probability of no impact on the mast S-glass epoxy longerons was calculated from the flux estimate, the projected surface area and the design lifetime. In estimating the micrometeoroids flux, a defocusing factor of 0.98 which accounts for the defocusing of the particle flux by the Earth gravitation was used to correct for this effect. Similarly, a flux factor (1) of 1.5 which accounts for the directionality of the debris flux with respect to the solar array normal and the velocity vector was used. It was assumed in this computation that a particle impact is damaging, and damage of one or more of the three longerons in one bay results in the mast failure. From the above assumptions, the damage criterion can be conservatively construed as the complete loss of mechanical properties of the impacted longeron which results in mast failure. Probability of impact of at most $n$ particles can be calculated from the cumulative Poisson distribution (1)

$$
P(n)=\sum_{r=0}^{n}\left[e^{\left(-A^{\star} F^{\star} T\right)^{\star}}\left(A^{\star} T^{\star} F\right)^{r}\right] / r !
$$

where. F(particles $/ \mathrm{m}^{2}$-year) is the flux, $A\left(\mathrm{~m}^{2}\right)$ is the exposed area, $T$ (year) is the time and. $r$ is the summation index. Probability of no impact (or zero impact) reduces $\mathrm{Eq} .1$ to

$$
P(0)=e^{-A^{*} F^{*} T}
$$

Given $P_{i}$ as the probability of no impact of the $i$ th longeron in one bay, and $Q_{j}$ is the probabil$i$ ty of one or more impacts on the ith longeron in the same bay, the following is true (4),

$$
P_{i}=1-Q_{i}
$$

and,

$$
\sum_{x=0}^{N} \frac{N !}{x !(N-x) !} P_{i}^{x} Q_{i}^{(N-x)}=1
$$

where $N=3$ because there are three longerons in parallel in one bay. Considering the impact of one or more longerons in a bay as a bay failure, the probability of one bay meeting the lifetime requirement is

$$
\begin{array}{r}
P(\text { bay })=1-\sum_{x=0}^{2} \frac{3 !}{x !(3-x) !} P_{i}^{x} Q_{i}^{(3-x)} \\
=P(0)^{3}=e^{-3^{\star} A^{\star} F^{\star} T}
\end{array}
$$

Moreover, since there are 75 bays in one mast, and since the failure of one bay affects the whole mast, the probability of the mast meeting the lifetime requirement is given by (5),

$$
P(\text { mas } t)=P(\text { bay }) 75
$$

\section{Solar Array Blanket}

The back surface of the solar cell string, (consisting of eight cells in series and one bypass diode in parallel as shown in Fig. 3), was considered for probability of impact analysis of panels and blanket of the solar array. Impacts on the front surface of the solar cells were not assessed because the solar cell is much thicker than the Kapton substrate. Using the geometry depicted in Fig. 3, the probability of no open circuit panel due to meteoroids and debris impact was calculated from the probability of no impact on both the photo-etched circuits connecting two consecutive cells and the circuits connecting cells with the bypass diode. The probability of no open string that, when open, results in an open panel can be summarized by,

$$
\begin{gathered}
P(\text { string })=\left[1-\left(1-e^{-A_{1} F T}\right)^{2}\right] 6\left[1-\left(1-e^{-A_{2 s} F T}\right)\right. \\
\left.\left(1-e^{-A_{2 l} F T}\right)\right]\left(1-e^{-2 A_{3} F T}\right)+e^{-2 A_{3} F T}
\end{gathered}
$$

where the areas $A_{1}, A_{21}, A_{25}$, and $A_{3}$ are shown in Fig. 3. Since there are 25 strings/panel which can be modeled in series, the probability of no open panel in the meteoroids and debris environments becomes ( 5 ),

$$
P(\text { pane } 1)=P(\text { string }) 25
$$

Since there are $N$ panels in one blanket. $(N=82$ for the space station solar array) and since the panels are protected by blocking diodes, the probability of at least $K$ unopen panels from the $N$ panels/blanket can be obtained by ( 4 and 5),

$P(P($ pane 1$) ; K, N)=\sum_{X=K}^{N}\left(\begin{array}{l}N \\ k\end{array}\right) P(\text { pane } 1)^{X} Q(\text { pane } 1)^{(N-X)}$

where $\left(\begin{array}{l}N \\ x\end{array}\right)$ is the binomial factor given by,

$$
\begin{gathered}
\left(\begin{array}{l}
N \\
x
\end{array}\right)=\frac{N !}{x !(N-x) !} \\
\text { RESULTS }
\end{gathered}
$$

\section{Solar Array Mast}

Results from Eq. (6) are displayed as the probability of the mast success as a function of the particle diameter of meteoroids or debris. Figures 4 and 5 show the aforementioned results for 15 years. Assuming that the damaging particle size is known, and the damaging criterion already defined applies, the aforementioned figures can be used to determine the probability of the mast in meeting the design lifetime requirement. 


\section{Solar Array Blanket}

Equation ( 9 ) is used to calculate the probability that at the end of life, at least $K$ panels (from $N$ panels/blanket at the beginning of life) are functional in the meteoroids and debris environments. For a space station solar array blanket, $N$ was taken as 82 and $K$ as 80 panels. Results of analyzing the cases for 15 and 4 year lifetimes are shown in Figs. 6 and 7 for the meteoroids and debris environments.

Figures 8 and 9 show the probability of success of the solar array blanket (which is the probability of success of at least $K$ panels at the end of life from $N$ panels at the beginning of life) for different particle size and different levels of redundancy. It is apparent that the probability increases with redundancy and particle size. The increase with particle size is due to the lower flux at larger diameter. Figure 8 shows that over the design lifetime of 4 years, and for impacting particles of 0.003 and $0.004 \mathrm{~cm}$ in diameter, the calculated probability of success of a blanket with 10 redundant panels is practically zero. This is explained by the higher meteoroids flux impinging on the back surface of the blanket. The same feature is illustrated by Fig. 9 for the debris environment for particle size of $0.001 \mathrm{~cm}$ or smaller. To calculate the mission time at which the blanket probability of success (or the probability of meeting the power requirement with a specific redundancy) decreases significantly. Eqs. 7 to 9 were evaluated for different lifetimes, and Figs. 10 and 11 were generated.

Figure 10 shows the probability of success of at least 80 panels at the end of life from 90 panels at the begining of life, as function of mission time for the two meteoroid size particles of 0.003 and $0.004 \mathrm{~cm}$. It is shown from this figure that the probability decreases significantly at approximately 0.5 and 1.25 years for the 0.003 and $0.004 \mathrm{~cm}$ particle diameter respectively. Figure 11 displays the same type of information with 10 redundant panels and no redundancy for a debris particle size of $0.001 \mathrm{~cm}$ in diameter. From Fig. 11, the probability was shown to decrease rapidly at approximately 0.35 and 2.5 years of design lifetime for a blanket with no redundancy and with 10 redundant panels respectively.

\section{CONCLUDING REMARKS}

An analysis was performed to assess the probability of success of the space station solar array subassemblies in the meteoroids and debris environment as a function of particle diameter. This analysis could complement a penetration model which determines the damaging particle size, and a damage model which correlates the particle size with the damaged areas. Therefore, a penetration and damage models are needed for the mast and substrate of the solar array blanket in order to compute the probability of the array meeting the power requirement in the meteoroids and debris environment. Such information will help determine the adequacy of the blanket design and the meteoroids and debris environmental oversizing factors used to size the space station solar array.

\section{ACKNOWLEDGMENT}

The author wishes to acknowledge all the reviewers of this paper from the Photovoltaic Power Module Division and especially D.J. Hoffman from the System Engineering and Integration Division of the Space Station Directorate for their time and constructive comments.

\section{REFERENCES}

1. N. Elfer, and G. Kovacevic, "Design for Space Debris Protection," in Man's Permanent Presence in Space, AIAA, New York, 1985.

2. "Solar Array Filight Experiment," Lockheed Missiles and Space Company, NASA Contract NAS 8-31352, Submitted to NASA Marshall Space Flight Center, Apr. 1986.

3. "Planar Solar Arrays for Space Station," Lockheed Missiles and Space Company, Inc., Sunnyvale, CA, 1984.

4. J.P. Wright, "Optimization of Large Heat Pipe Radiators for Long Life Heat Rejection Missions," ASME Paper 79-ENAS-25, July 1979.

5. I. Miller, and J.E. Freund, Probability and Statistics for Engineers, Second Ed., Englewood Cliffs; NJ: Prentice-Hall, 1977. 


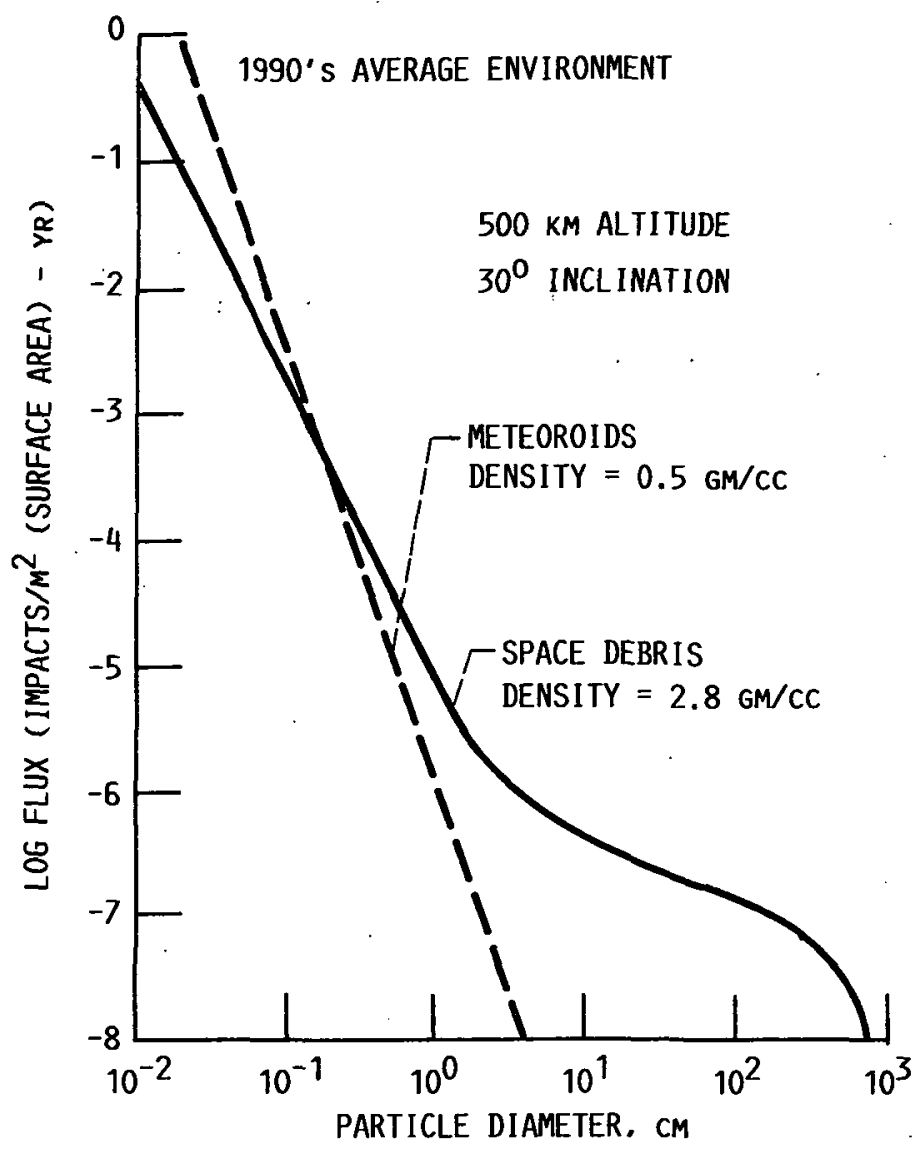

FIGURE 1. - FLUX OF METEOROIDS AND SPACE DEBRIS AS A FUNCTION OF DIAMETER FOR A $500 \mathrm{KM}$ ORBIT. THE METEOROID FLUX IS CORRECTED FOR EARTH SHIELDING.

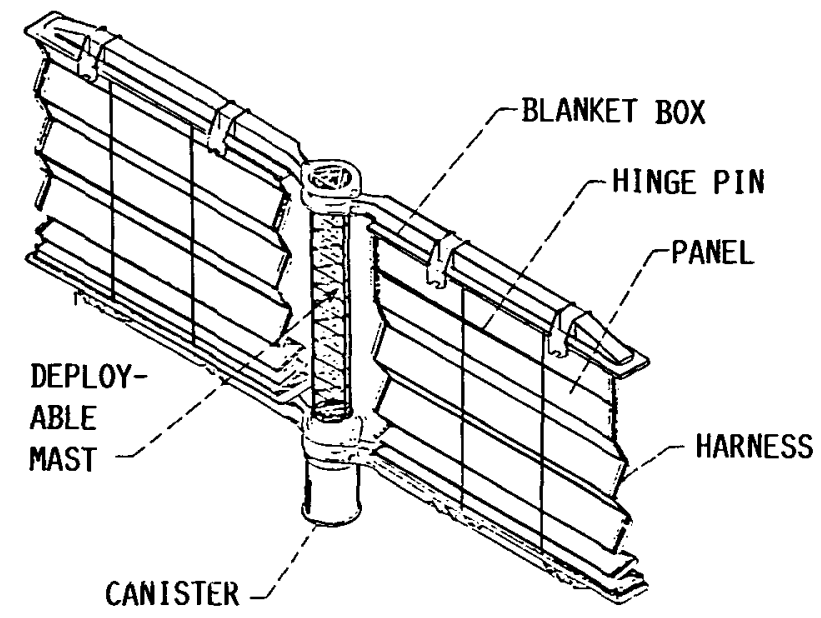

FIGURE 2. - DEPLOYABLE RETRACTABLE SOLAR ARRAY STRUCTURE FOR THE SPACE STATION PHOTOVOLTAIC POWER MODULE. 


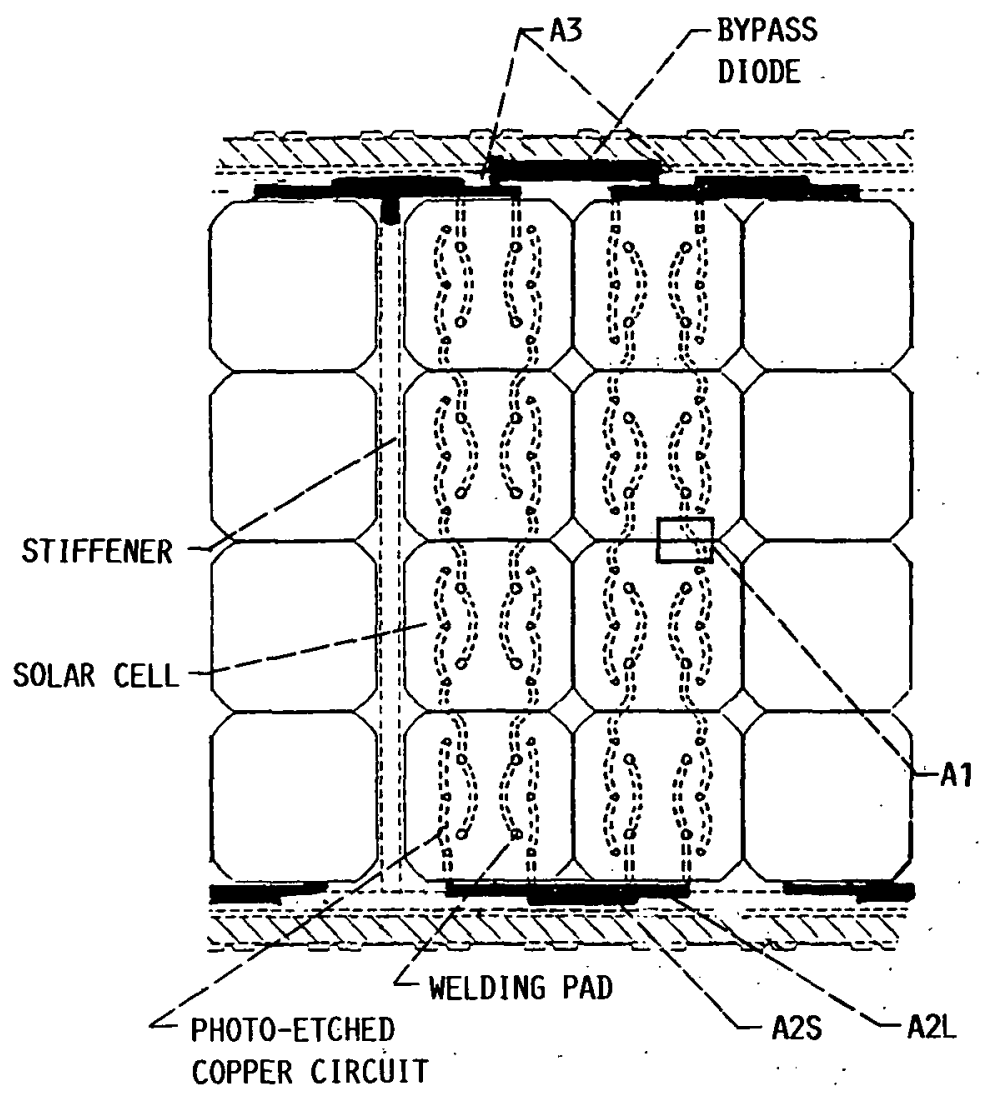

(A) SOLAR CELL STRING INVESTIGATED FOR OPEN CIRCUIT PROPABILITY DUE TO PARTICLE IMPACTS.

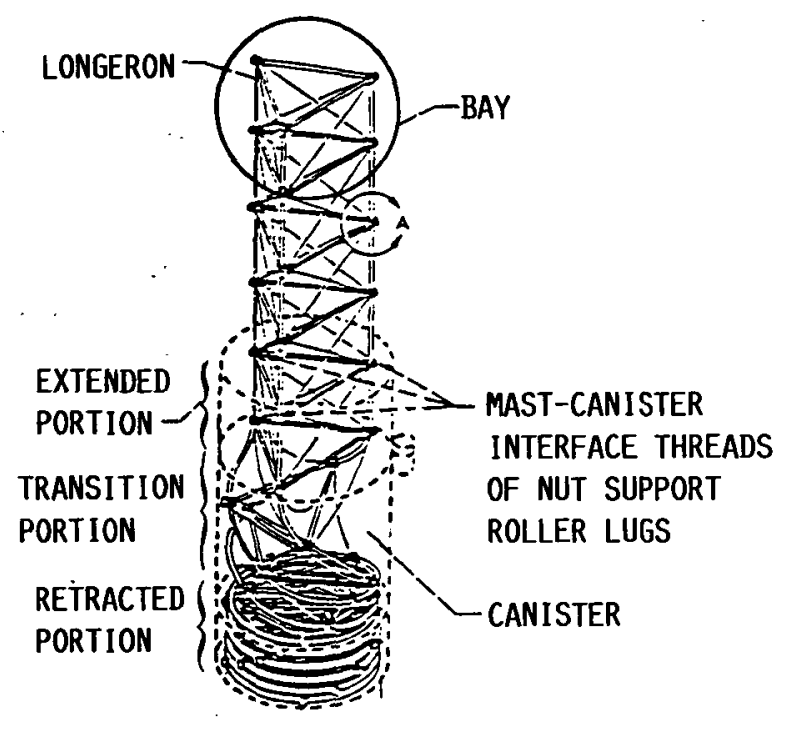

(B) LONGERON, BAY AND MAST STRUCTURE INVESTIGATED FOR IMPACT PROBABILITY.

FIGURE 3. - REPEATING STRUCTURES IN THE SOLAR ARRAY MAST AND BLANKET CONSIDERED FOR PROBABILITY OF IMPACT ANALYSIS. 


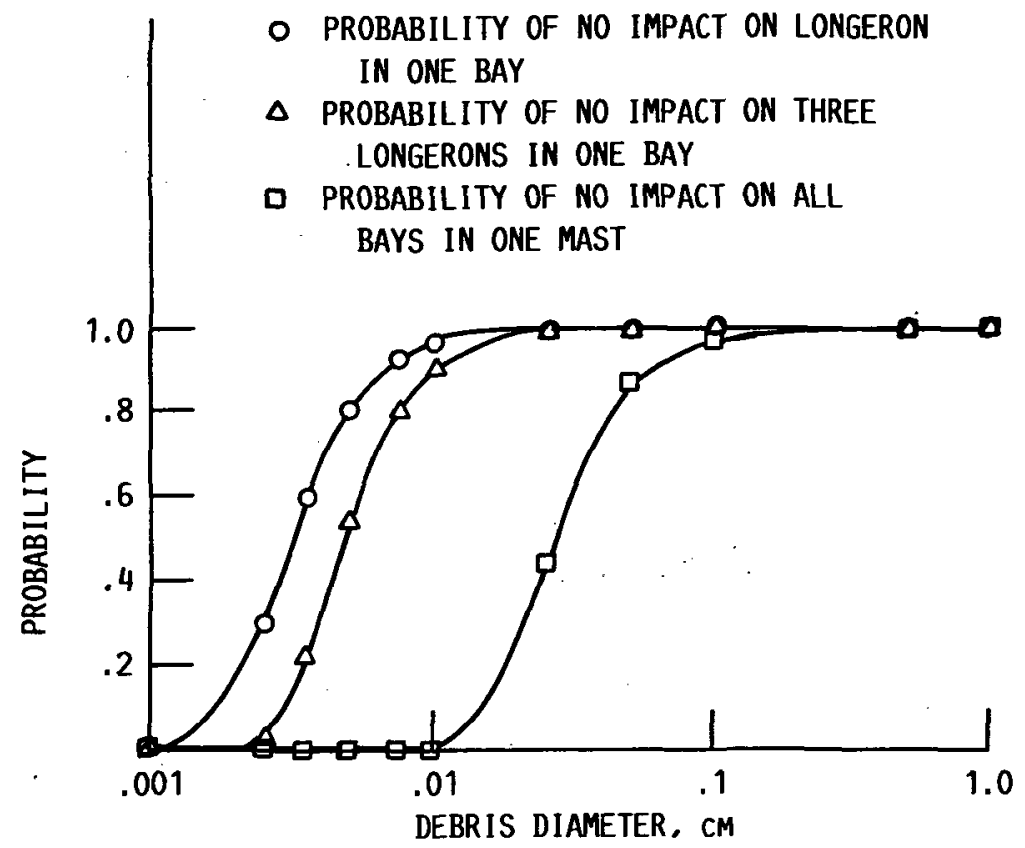

FIGURE 4, - PROBABILITY OF SUCCESS VERSUS DEBRIS FOR LONGERON, BAY AND SOLAR ARRAY MAST FOR 15 YEARS DESIGN LIFETIME.

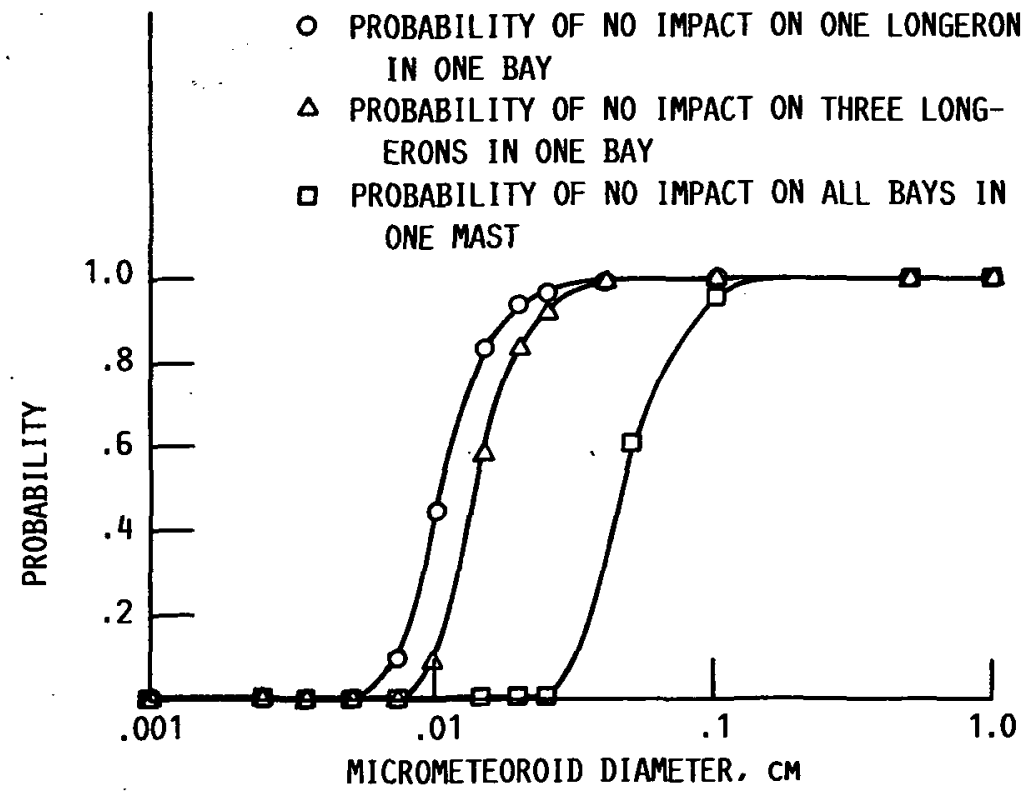

FIGURE 5. - PROBABILITY OF SUCCESS VERSUS MICROMETEOROID DIAMETER FOR LONGERON, BAY, AND SOLAR ARRAY MAST FOR 15 YEARS DESIGN LIFETIME. 


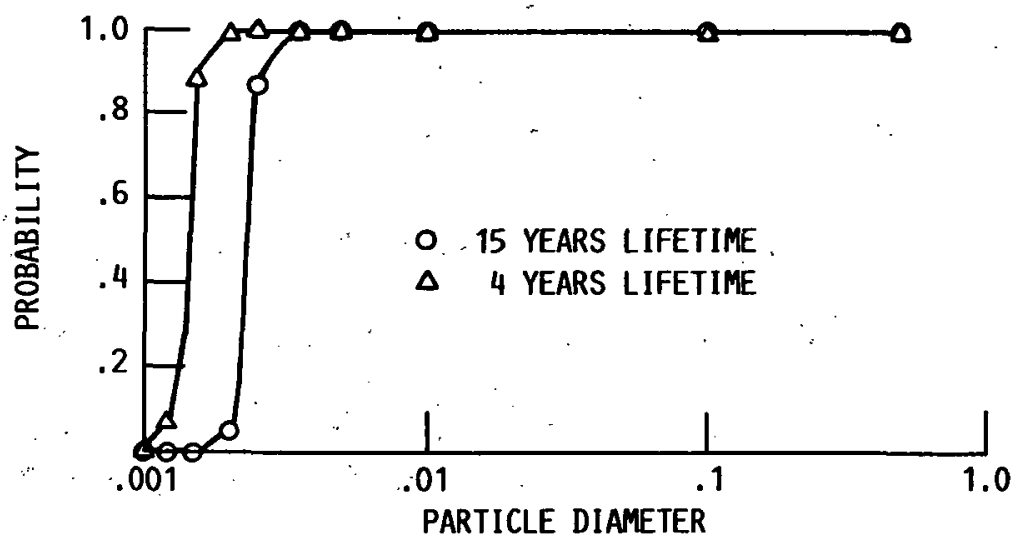

FIGURE 6. - PROBABILITY OF SUCCESS VERSUS DEBRIS DIAMETER FOR A SPACE STATION SOLAR ARRAY BLANKET WITH TWO REDUNDANT PANELS.

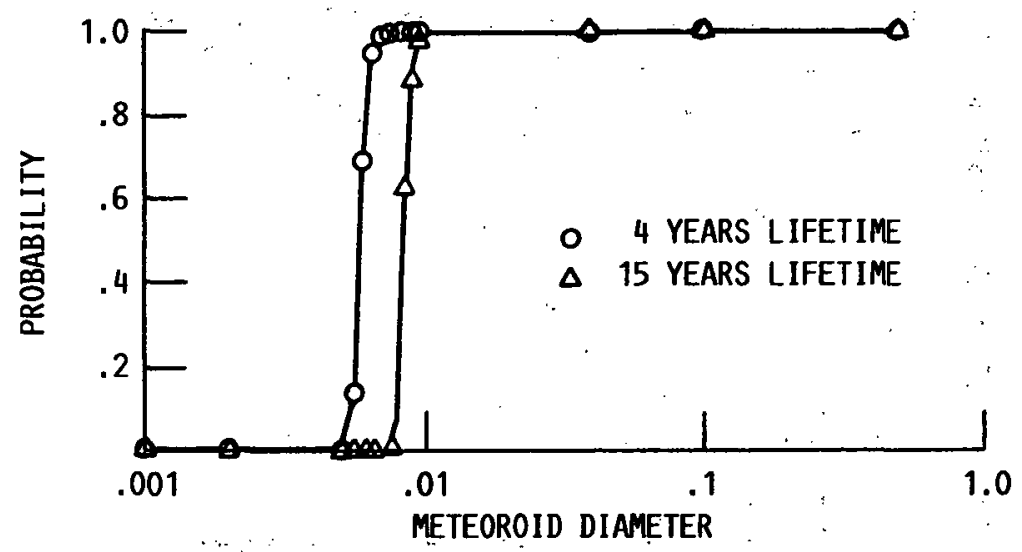

FIGURE 7. - PROBABILITY OF SUCCESS VERSUS METEOROID DIAMETER FOR A SPACE STATION SOLAR ARRAY BLANKET WITH TWO REDUNDANT PANELS. 


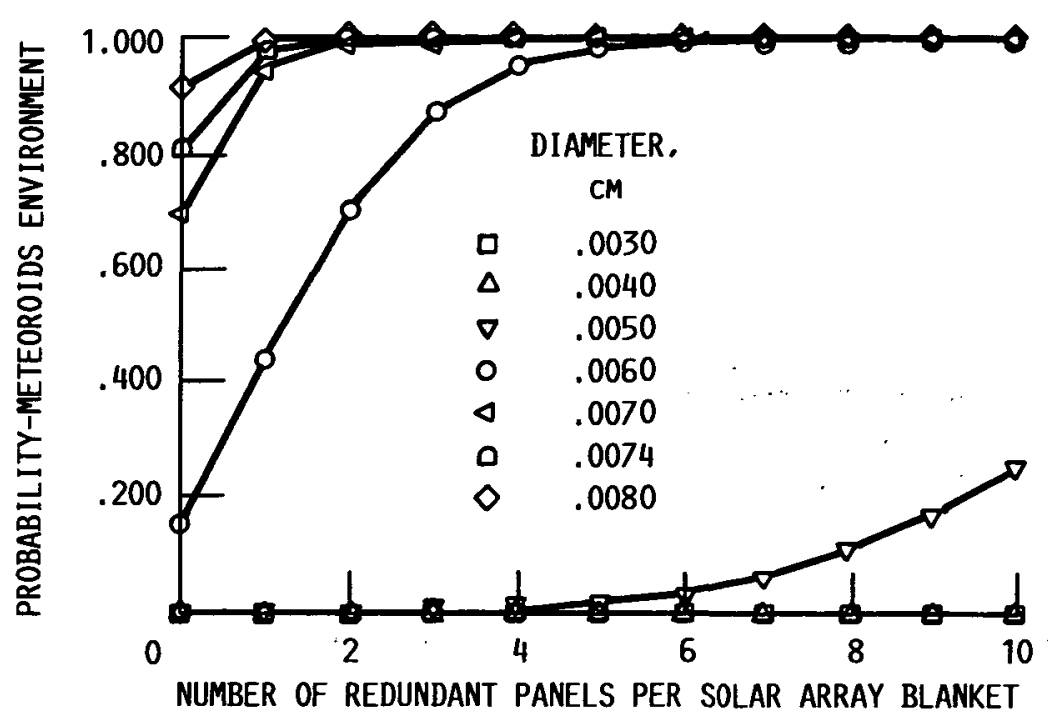

FIGURE 8. - PROBABILITY OF SUCCESS VERSUS REDUNDANCY OF SOLAR ARRAY BLANKET FOR 4 YEARS DESIGN LIFETIME IN THE METEOROIDS ENVIRONMENT.

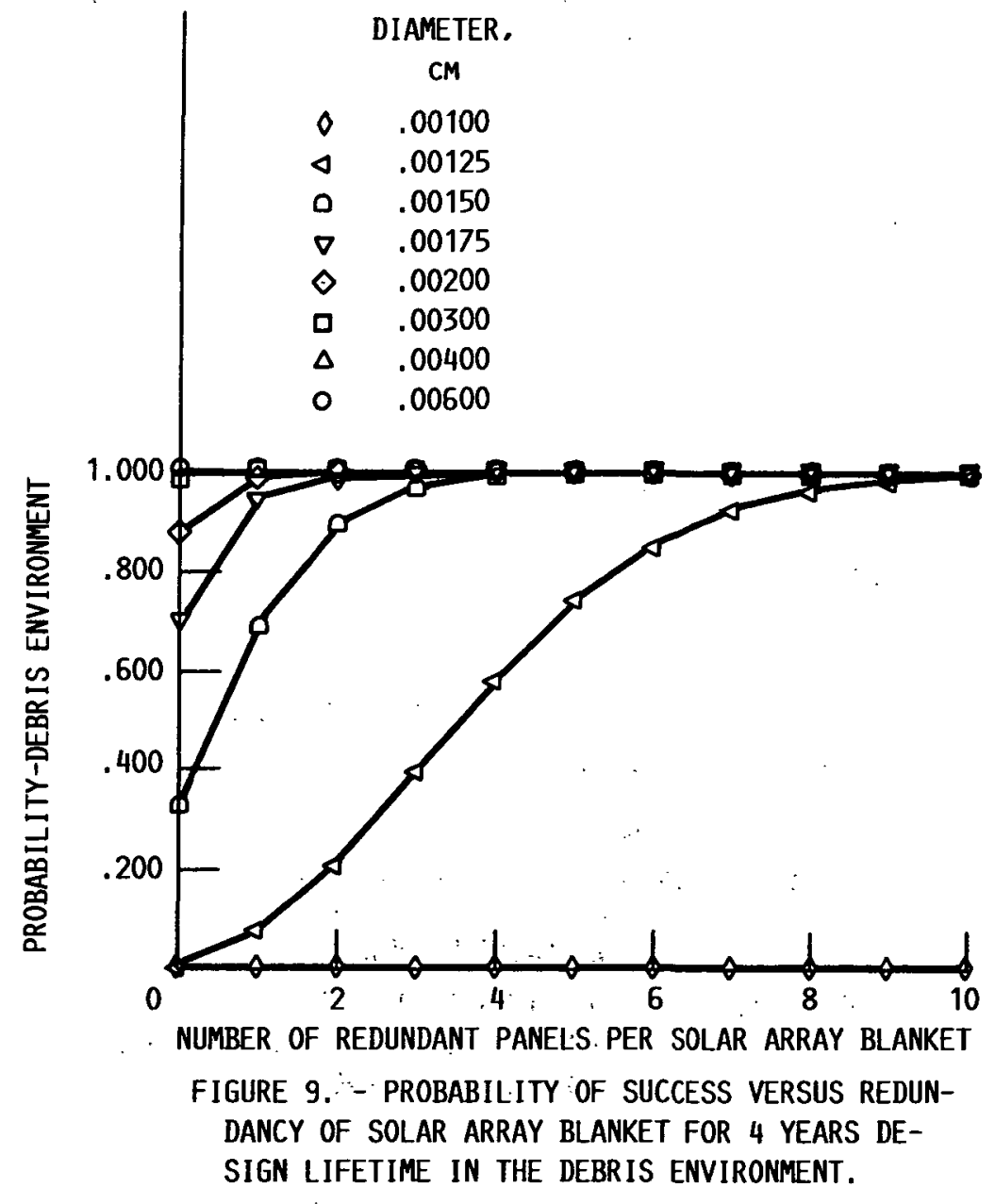




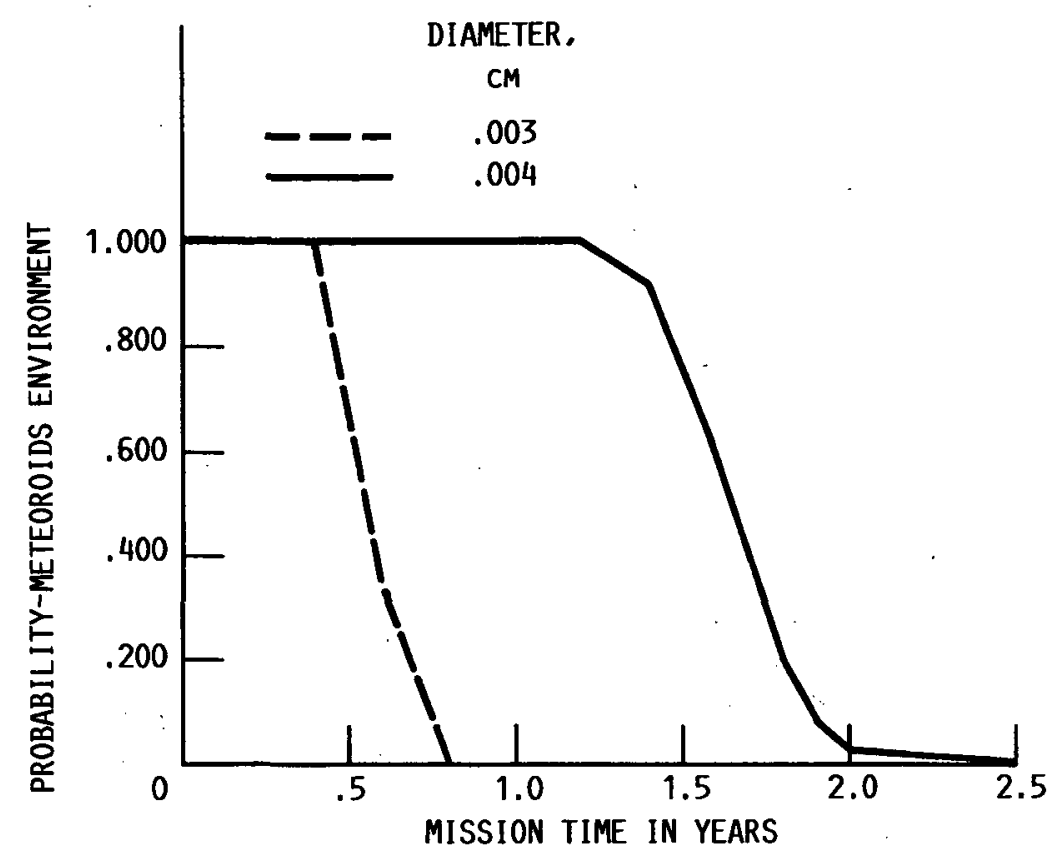

FIGURE 10. - PROBABILITY OF SUCCESS VERSUS MISSION TIME OF A SOLAR ARRAY BLANKET FOR TWO METEOROID DIAMETERS AND 10 REDUNDANT PANELS/BLANKET.

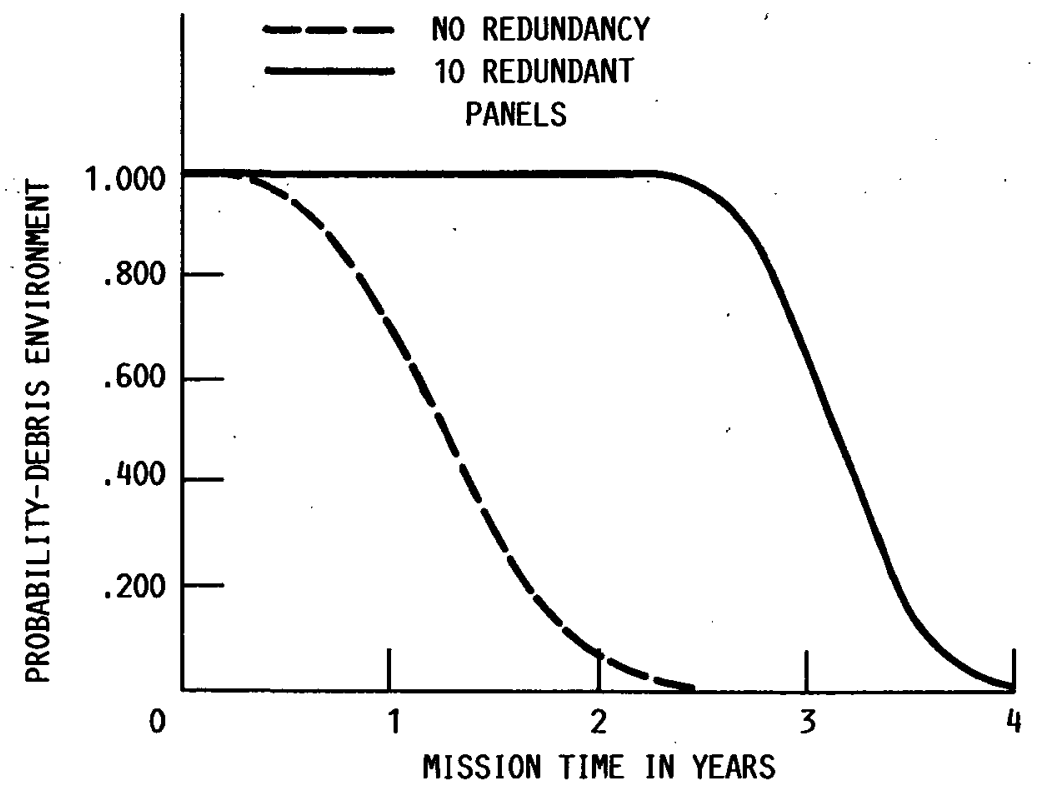

FIGURE 11. - PROBABILITY. OF SUCCESS VERSUS MISSION TIME FOR .001 CM DEBRIS PARTICLE DIAMETER, 


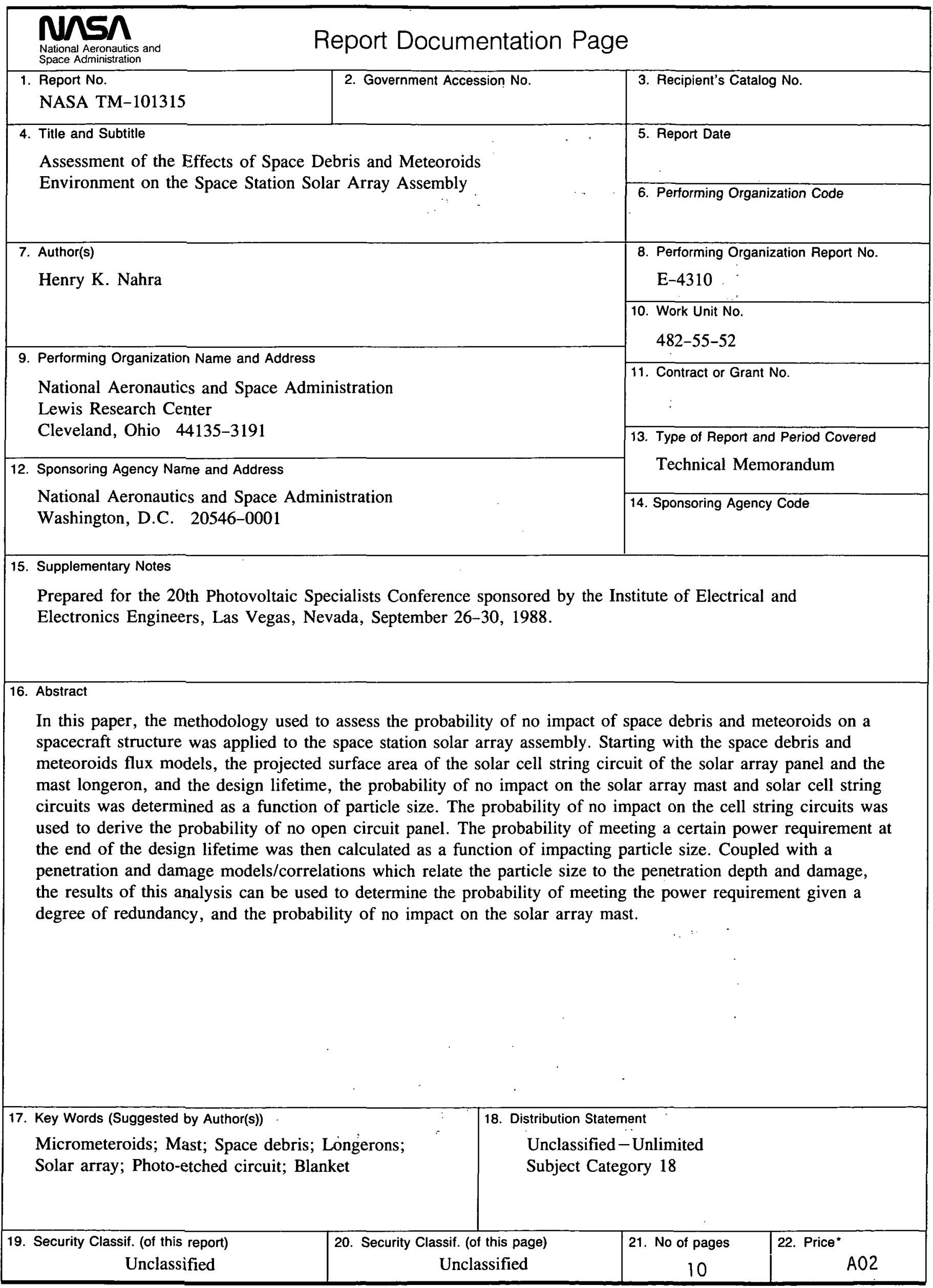


National Aeronautics and Space Administration

Lewis Research Center

Cleveland, Ohio 44135

Otficial Business

Penaity for Private Use $\mathbf{\$ 3 0 0}$

Posiage and Fees Patd

National Aeronautics and

Space Admunistratıon

NASA 451 